\title{
FLOW CHARACTERIZATION FROM A NACA AIR INTAKE ASSEMBLED IN A CANARD TYPE AIRCRAFT
}

\author{
O. de Almeida, \\ and P. R. C. Souza \\ Centro de Pesquisa em Aerodinâmica \\ Experimental - CPAERO \\ Faculdade de Engenharia Mecânica \\ Av. João Naves de Ávila 2121 \\ Campus Santa Monica \\ CP. 38408, Uberlândia, Minas Gerais, Brazil \\ odenir.almeida@ufu.br \\ pedro_ricardo@mec.ufu.br \\ Received: September 11, 2016 \\ Revised: April 30, 2017 \\ Accepted: May 31, 2017

\section{ABSTRACT} \\ Computational aerodynamics analyses of a NACA air intake assembled in a \\ canard type aircraft is performed in this work. Semi-empirical calculation \\ through the ESDU (Engineering Science Database Unit) preceded the CFD \\ simulations to define the geometric size of the air intake as well to check its \\ efficiency and drag estimation. The NACA air inlet was considered one of \\ the best options available for implementing in a canard type aircraft since it \\ reduces aerodynamic drag by avoiding protuberances in the fuselage. \\ Numerical studies were performed with the air intake mounted in the \\ aircraft's fuselage at operational flight conditions. These simulations were \\ performed using Reynolds-averaged Navier-Stokes (RANS) and turbulence \\ modeling by using the k- $\omega$ SST (Shear-Stress Transport). Data analyses \\ were based on the air inlet efficiency, drag estimation and mainly flow \\ characterization. The numerical results helped to characterize the flow in a \\ canard type aircraft showing that the NACA air intake yielded satisfactory \\ performance with low drag. The approach applied in this work was a \\ partnership with the Brazilian Aircraft Factory (FABE) and Federal \\ University of Uberlândia (UFU) to improve the design of a canard type \\ aircraft. The CFD results have been corroborated by an empirical approach \\ and with some experimental tests performed by the company, pointing \\ towards the reliability of a very efficient design tool for application in \\ industry. \\ Keywords: air inlet, efficiency, drag, CFD
}

\section{NOMENCLATURE}

$\mathrm{A}_{1} \quad$ inlet highlight capture area, $\mathrm{m}^{2}$

$\mathrm{C}_{\mathrm{d}} \quad$ drag coefficient

$\mathrm{C}_{\mathrm{Dfl}}^{\prime}$ spillage drag at zero mass flow

Ln length of flush inlet, $\mathrm{m}$

M Mach number

$\dot{\mathrm{m}} \quad$ mass flow entering inlet, $\mathrm{kg} / \mathrm{s}$

$\mathrm{w}$ highlight width of inlet, $\mathrm{m}$

$\mathrm{x}, \mathrm{y}, \mathrm{z}$ cartesian coordinates, $\mathrm{m}$

$\delta \quad$ boundary layer thickness, $m$

\section{Greek symbols}

$\alpha \quad$ ramp angle, degree

$\eta \quad$ ram pressure efficiency

$\theta$ boundary layer momentum thickness

\section{Subscripts}

$\begin{array}{ll}\text { inf } & \text { conditions at infinity } \\ \text { o } & \text { free stream } \\ \text { th } & \text { throat }\end{array}$

\section{INTRODUCTION}

One of the most common air intakes of aerial and terrestrial vehicles are the NACA inlets. Such devices were originally designed by the National Advisory Committee for Aeronautics (NACA) and were quickly spread in the aeronautical industry since they were conceived to reduce drag by not having external protuberances into the main flow, while at the same time providing fresh air to several systems in the aircraft.

NACA air intakes, also called NACA ducts have no external projections, as shown in Fig. 1, resulting in low aerodynamic drag at the same time that not demand specific structural reinforcements, causing no impact on the weight of aircraft (Silveira et al. 2017).

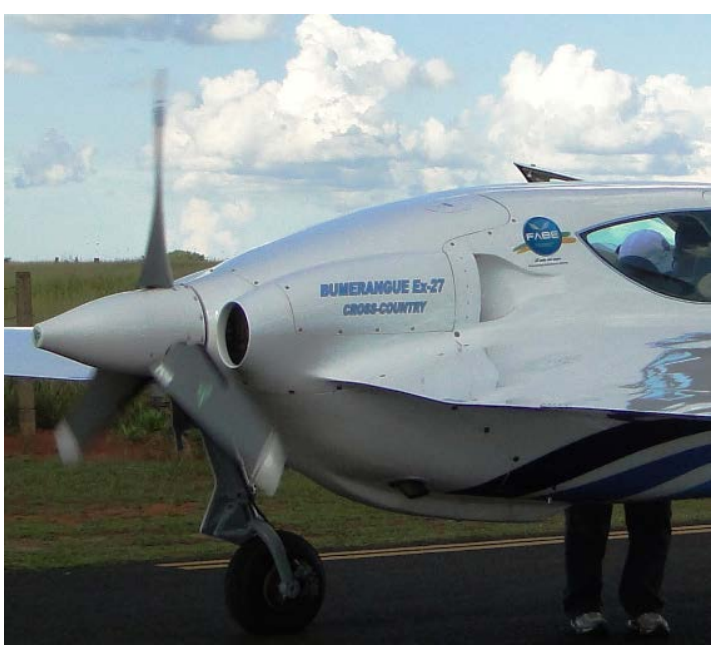

Figure 1. Air inlet type NACA (Courtesy of FABE Ltd.). 
The low efficiency of this type of air intake is often listed as a disadvantage especially when compared to other inlets such as the scoops. Basically, the penalty in efficiency is due to the incoming flow from the boundary layer as it is submerged. Its basic operation is based on the deviation of the air flow into the throat of the inlet, this deviation caused by the diverging slope and by the generation of vortices in their sidewalls.

As discussed by Silveira et al. (2017), a few studies used CFD techniques to analyze air inlets for different types of applications (Taskinoglu, et. al (2002)). Sun and Guo (2005) also investigated the flow-field of a NACA inlet by inspecting the total pressure distribution at the exit of the inlet as well as its performance.

Shams and Masud (2015) evaluated through computational analysis NACA flush inlets at high subsonic and supersonic free stream Mach numbers. To evaluate the performance of the air inlets the mass flow rate, the ratio between the entry mass flow and the theoretical mass flow under conditions of undisturbed flow and total pressure recovery were investigated. These parameters have been commonly used to characterize the performance of such air intakes.

Alternatives to increase the efficiency of NACA air intakes were seen with the use of vortex generators (de Faria and Oliveira, 2002). In particular, some Boeing 737's have this kind of inlet for feeding the Auxiliary Power Unit (APU) located in the tail. Despite the lack of information available in literature there is always a tradeoff between efficiency and drag that must be carefully analyzed for these types of air inlets.

Pignier et al. (2016) presented a computational aerodynamics and aeroacoustic analyses of a submerged air inlet a low Mach number. This work was new in terms of showing acoustic spectra and its correlation with the flow parameters. Despite the absence of experimental data for comparisons purposes the computational analysis was used to estimate the location and the quantification of the sound sources generated by the flow around the inlet.

Despite the appearance of computational studies related to NACA air inlets, the most reliable set of data of conventional air inlets is published in Engineering Sciences Data Unit, ESDU (item $\mathrm{n}^{\circ}$ 86002, 1986). This database has been used to help the development of new air intakes which could be improved by computational analyses later on.

As part of an ongoing research the goal of this work is twofold: firstly to help the development of a new canard-type aircraft in Brazil through a partnership between the Brazilian Aircraft Factory (FABE Ltd.) and the Experimental Aerodynamics Research Center (CPAERO) at Federal University of Uberlândia, by means of developing guidance rules for designing and implementing air intakes in such vehicles. Secondly, in this study, a Computational Fluid Dynamics approach was used to characterize the flow from a NACA air intake in a canard airplane. A first calculation was consolidated in the work of Silveira et al. (2017) which presented a simpler approach to investigate the effect of fuselage's curvature in the NACA air inlet. In that case, the influence of the canard was not taken into consideration.

In this study, the flow field around the complete canard airplane was simulated through incompressible RANS simulations by employing the $\mathrm{k}-\omega$ SST turbulence modeling in the well-known CFD++ commercial code from Metacomp Inc ${ }^{\circledR}$. Simulations were performed at a Mach number of 0.178 for a duct depth of $\mathrm{d}_{\mathrm{t}}=6.0 \times 10^{-2} \mathrm{~m}$. An analysis based on the flow inside the NACA inlet, efficiency and drag are detailed in the following sections in order to evaluate the implementation feasibility of this component for a canard-type aircraft.

\section{ENGINEERING APPLICATION}

The Bumerangue EX-27 is a canard type aircraft classified in the general aviation category as an experimental vehicle since it is under development at the moment in Brazil by the Brazilian Aircraft Factory (FABE Ltd.). It is a quadriplace aircraft, front wing (canard) equipped with a single engine installed in the pusher configuration, Fig. 2.

During the development phase of this aircraft it was identified a need for special cooling (air ventilation) in the rear compartment where the engine is mounted, due to the use of possible different engine power plants. Currently the engine installed in the aircraft is a Continental TSIO 360 EB Turbo - air refrigerated developing $210 \mathrm{HP}$ at $2700 \mathrm{rpm}$. To assure the right air flow through the engine compartment additional air inlets must be assembled in the fuselage at the rear end of the aircraft. The options were scoops and NACA air inlets which have been addressed in this work. As mentioned before, the approach was to evaluate a NACA air intake design that would supply the required air for the engine compartment with a minimum penalty on drag for the whole aircraft and that would support further new power plants to be installed in the airplane. The main goal was to characterize the flow from the NACA and to evaluate its performance. The design of this air intake will be manufactured and incorporated in the airplane for doing experimental tests in the flight campaign.

According to the request of the airplane manufacturer two operational conditions were evaluated - table 1. The cruise condition was considered with the airplane flying with $2^{\circ}$ AOA (Angle of attack) and the most critical condition emulating a take-off flight path at $15^{\circ}$ AOA. It is expected a good performance of the air intake at 
these two conditions.

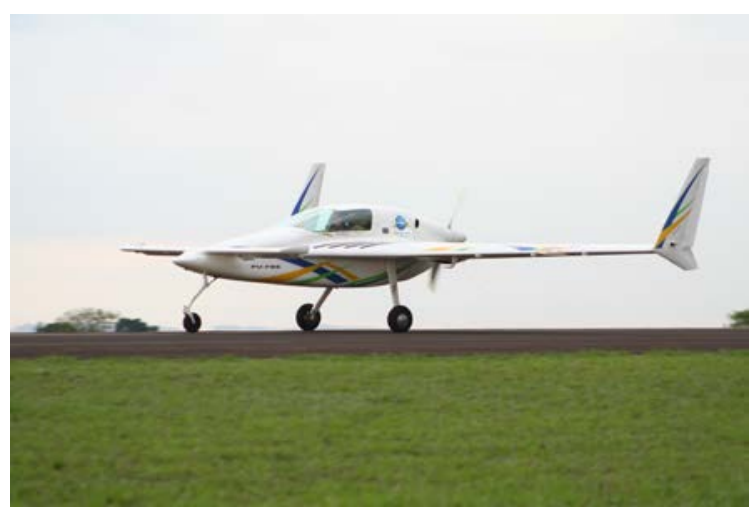

Figure 2. Bumerangue EX-27 Cross-Country airplane (courtesy of FABE Ltd.).

Table 1. Design conditions.

\begin{tabular}{|l|l|}
\hline \multicolumn{1}{|c|}{ Parameters } & Operational Condition \\
\hline Speed & 120 knots $(61.73 \mathrm{~m} / \mathrm{s})$ \\
\hline Angle of attack (AOA) & $2^{\circ}$ and $15^{\circ}$ \\
\hline Altitude & $3000 \mathrm{ft}(914.4 \mathrm{~m})$ \\
\hline Temperature & $25^{\circ} \mathrm{C}$ \\
\hline Density & $1.121 \mathrm{~kg} / \mathrm{m} 3$ \\
\hline Pressure & $90812 \mathrm{~Pa}$ \\
\hline
\end{tabular}

\section{NACA SIZING}

Previous calculations for sizing a NACA air intake for this canard type airplane have been performed in the work of Silveira et al. (2017) with the use of a well-known semi-empirical method, namely, ESDU (Engineering Science Database Unit) - ESDU (1986) and CFD simulations for accessing the pressure recovery at the NACA entry.

To predict and calculate the geometric and flow parameters from the flush inlet (NACA), Fig. 3, this semi-empirical method utilizes a catalogued database to compute the drag and pressure recovery of small auxiliary air inlets totally or partially immersed in the boundary layer. This approach is suitable at subsonic speeds. Essentially, the theory of two-dimensional boundary-layer calculation is used as reference and modified in the light of the available experimental data.

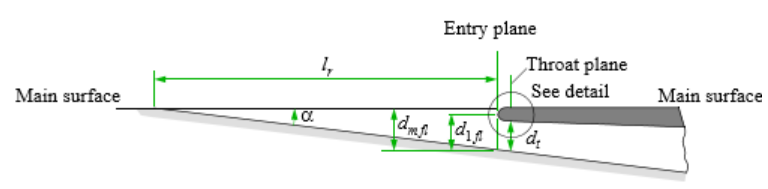

Figure 3. Scheme and parameters of the inlet designed - ESDU, 1986.

Considering the throat aspect ratio and a ramp angle as depicted on Table 2, the parameters calculation led to what was considered to be the minimum size of the flush inlet to provide the minimum amount of air to the engine compartment.

Table 2. Flush inlet design parameters.

\begin{tabular}{|c|c|}
\hline ESDU parameters & Units \\
\hline$\dot{m}$ & $0.016 \mathrm{slug} / \mathrm{s}$ \\
\hline$\delta_{n}$ & $0.1 \mathrm{ft}$ \\
\hline$\theta_{0}$ & $0.01 \mathrm{ft}$ \\
\hline$\alpha_{\text {ramp }}$ & $7^{\circ}$ \\
\hline$w / d t$ & 4 \\
\hline
\end{tabular}

Fig.4 illustrates the design for the inlet used in the previous simulations performed by Silveira et al. (2017).
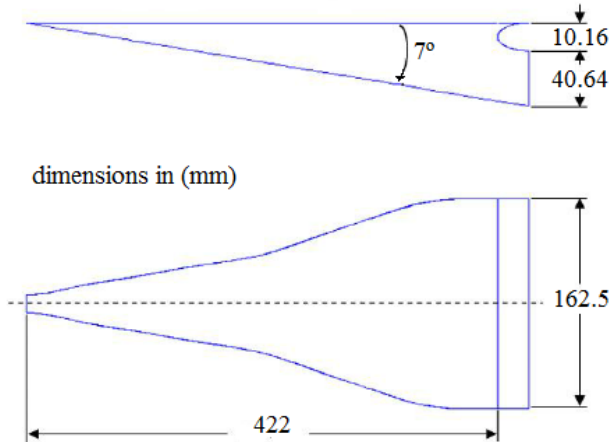

Figure 4. NACA air inlet sizing- Silveira et al. (2017).

As mentioned, due to the need of using a more powerful engine in this aircraft it was identified the necessity of increasing the mass flow through the engine compartment to avoid high temperatures during the operation of the aircraft.

A set of calculation using ESDU led to resizing the original design presented by Silveira et al. (2017). At the operational condition of the airplaine, the new mass flow has been targeted to 0.060 slug/s after a more detailed analysis and data verification with the engine's manufacturer. The inlet capture area has increased to $A_{1}=0.0146 \mathrm{~m}^{2}$ in order to comply with this requirement.

By applying the same calculation procedure as presented in Silveira et al. (2017), the values found were listed below:

$$
\begin{gathered}
d_{t}=0.060 \mathrm{~m} \\
w=d_{t} \times 4=0.24 \mathrm{~m} \\
l=t=0.25 \cdot d_{t}=0.015 \mathrm{~m}
\end{gathered}
$$

The maximum external height of the inlet, $d_{m f l}$ and the lip highlight height, $\mathrm{d}_{1 \mathrm{fl}}$, determined in the inlet plane relative to the ramp floor, are calculated by:

$$
d_{m f l}=d_{t}+t-l_{l} \tan \alpha=0.073 \mathrm{~m}
$$




$$
d_{1 f l}=d_{t}+0.5 t-l_{l} \tan \alpha=0.065 \mathrm{~m}
$$

with a mass flow ratio of $\frac{\dot{m}_{T}}{m_{0}} \approx 0.89$.

By following this procedure the new NACA air inlet design was targeted to mass flow instead of designing it for maximum efficiency. With the inlet dimensions determined, the calculation of the drag coefficient for the flush inlet $C_{\mathrm{Dfl}}$ and ram pressure efficiency $\eta_{f l}$ proceeded in an identical manner to that set out in Silveira et al. (2017). The values are summarized below:

$$
C_{\text {Dfl }}=1.328
$$

And:

$$
\eta_{f l}=0.727
$$

Therefore, using this tabulated semi-empirical approach it was possible to obtain the parameters for designing a new flush inlet - NACA, which final dimensions are specified in Figure 5.
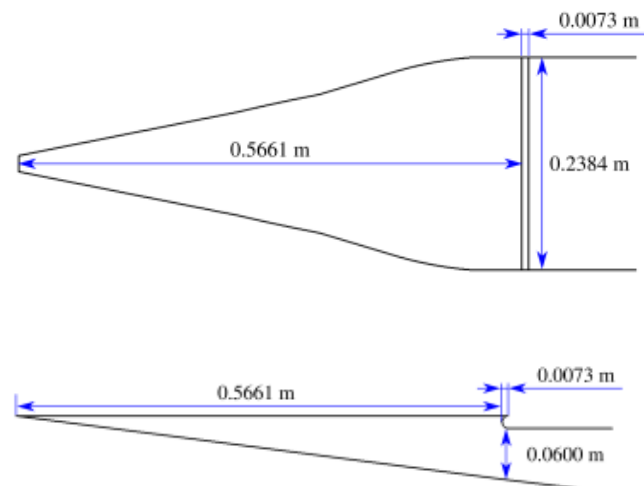

Figure 5. Resizing of the NACA flush inlet.

Additional details for this semi-empirical method can be found in the ESDU document Item No. 86002 (ESDU, 1986).

\section{FLUID DYNAMICS}

The flow simulations were run on the commercial software CFD++® (Metacomp user's manual, 2009) by means of a Reynolds Averaged Navier-Stokes (RANS) approach. As described in Silveira et al. (2017), the governing equations were solved with a second order accuracy through a Finite Volume formulation (FV). The computational results were obtained after 2000 iterations, or when the residuals dropped 5 orders of magnitude. For the turbulence modeling, the $\mathrm{k} \omega$-SST (Shear Stress
Transport, Menter (1993)) turbulence model was applied, based on experiences acquired in the past works with RANS equations applied to external flows with boundary layer detachment.

The CFD simulations were run to represent the flow over the complete aircraft's fuselage with the NACA air inlet assembled on it, in its actual position and under the operational conditions of the airplane. Differently from Silveira et al. (2017) the effect of the front wing (canard) was taken into account. As it will be shown the canard has influence in the main flow, especially when the angle of attack varies.

A summary of the computational domain and the mesh for the whole aircraft configuration will be shown in the next subsection.

\section{Computational Domain}

The computational domain was a hemisphere of radius 50.5 times the length of the aircraft (L). Fig. 6 illustrates the domain out of scale for better visualization. The size of this domain was selected based on previous studies (de Faria and Oliveira, 2002). The values shown below were considered suitable for such kind of simulation avoiding the effect of the boundary condition in the final computed values for the internal flow field solution.

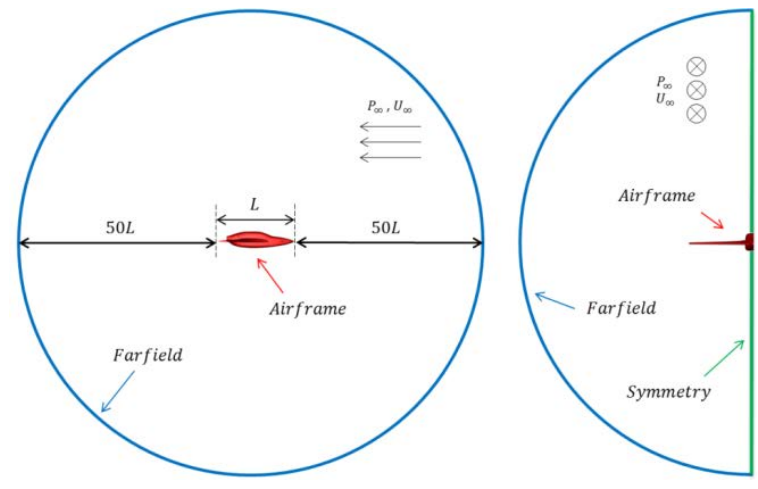

Figure 6. Computational domain based on the Aircraft's length $(L)$.

Mesh

The mesh, shown in Fig.7, was generated in Ansys ${ }^{\circledR}$ IcemCFD software. The discretization for the whole aircraft consisted of an unstructured mesh of triangles (surface mesh) and tetrahedrons (volume meshes) with approximately 9 million elements, with some refinements (density grids) on the desired regions of the flow, close to the air intake and downstream. To discretize the boundary layer development a prism-layer region was applied around the surface walls from the airplane.

The generated mesh was carefully handled to avoid large discrepancy in the size of the elements and poor quality especially in the region where is placed the air intake. Some prior tests were 


\section{Tecnologia/Technology}

performed with coarser meshes such as 2.2 million, 4.1 million, and 6.0 million mesh size. With the prism layer region added the final mesh reached 9 million of elements giving a satisfactory result in terms of the flow field characterization.

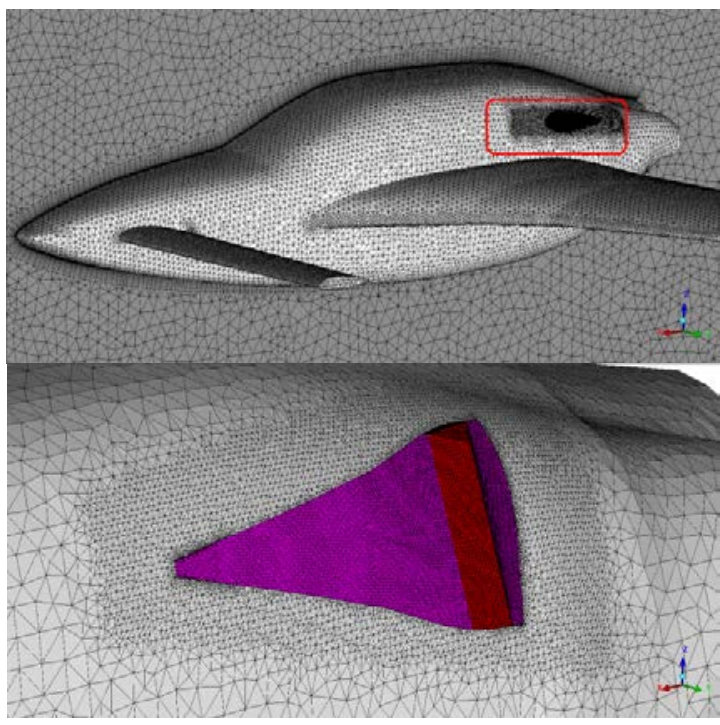

Figure 7. Mesh details: a) full airplane; b) NACA in the fuselage.

\section{Boundary Conditions}

A so-called free stream boundary condition was used to represent the ambient atmospheric flight level where pressure and temperature were set to $90812 \mathrm{~Pa}$ and $298.15 \mathrm{~K}$, respectively. All solid surfaces were set as no-slip wall and adiabatic boundaries. As seen in Fig. 8 the outer boundary was placed far away from the body where the far field condition was assumed with minimum possibility of disturbing the internal domain solution. As a hemisphere was used, only half-airplane was simulated by imposing a symmetry plane cutting $\mathrm{z}=0$.

\section{RESULTS AND DISCUSSION}

A good air intake sizing is achieved when the air flow that enters it is enough to keep the engine cooled in any flight condition, with a minimal drag addition and maximum efficiency. Basically, the flow field in and around a NACA air intake at low Mach number consists of a part of the free stream airflow which is forced into the inlet due to the effect of the counter-rotating vortices that are formed on the sidewalls of the NACA. The presence of these vortices are important to define the flow dynamics, however the strength of them are also responsible for what is called spillage, translating by an increase in the aerodynamic drag.

First, the global effect of $\alpha$ (angle of attack) in the flow around the airplane and in the close proximity of the NACA air intake was analyzed. The angles of attack of $2^{\circ}$ and $15^{\circ}$ were tested and Fig. 8
Almeida and Souza. Flow Characterization from a NACA...

shows the symmetry plane with velocity stream lines for these flight conditions analyzed.

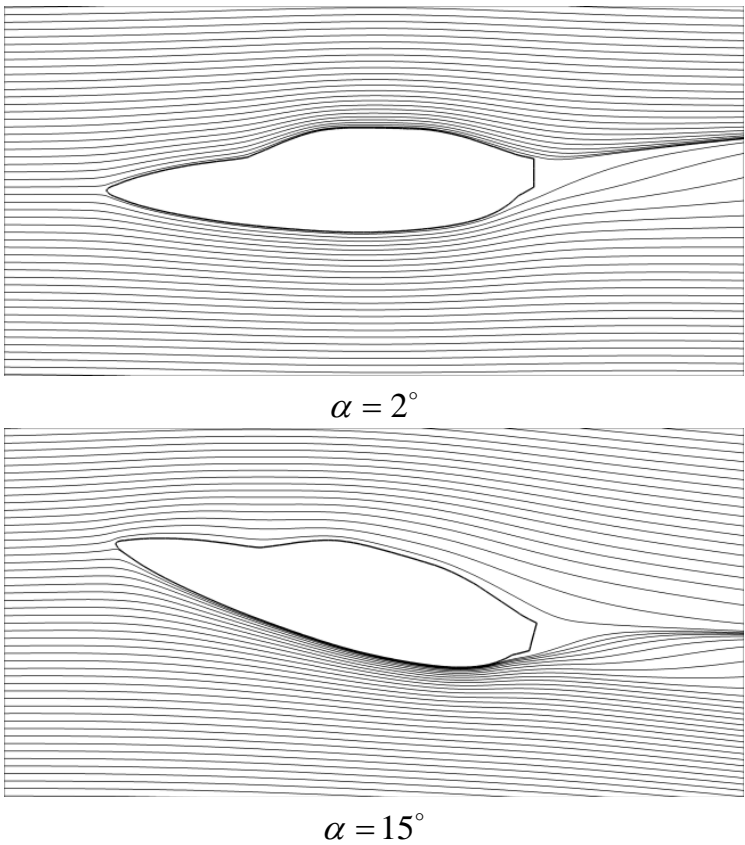

Figure 8. Streamlines in the symmetry plane for AOA $\alpha=2^{\circ}$ and $\alpha=15^{\circ}$, respectively.

The flow pattern changes dramatically as the angle of attack $(\alpha)$ modifies affecting the region where the NACA air intake is assembled. Only inspecting this result it was not possible to affirm that the flow pattern around and in the NACA entry was disturbed.

Fig. 9 shows the velocity path lines entering the NACA air intake for the two test-cases. The flow pattern is well organized in the cruise condition ( $\alpha=2^{\circ}$ ) passing along the fuselage and entering the NACA inlet being part of it spilled and forming a wake behind the aircraft.

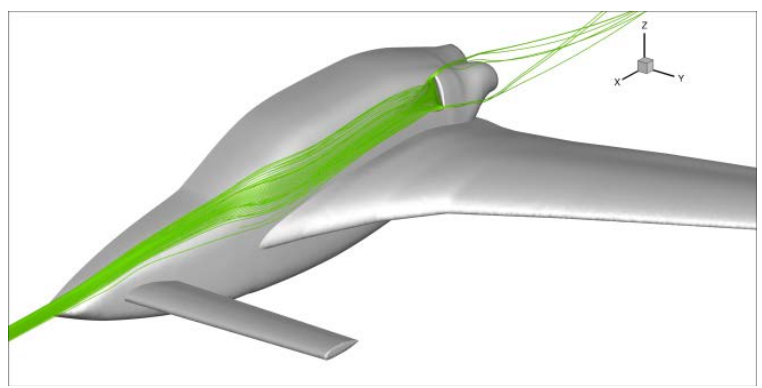

(a) $\alpha=2^{\circ}$

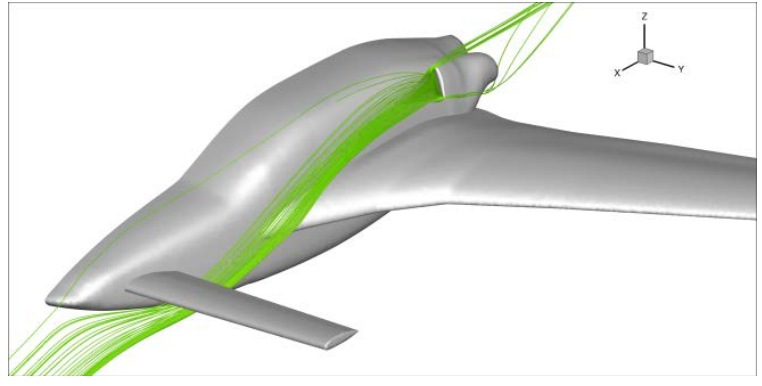


(b) $\alpha=15^{\circ}$

Figure 9. Path lines entering the NACA air intake under the canard effect.

What is interesting to notice in Fig. 9(b) is that due to the wing shape and upwash the flow is diverted into the NACA location entering it with a relatively undisturbed wake. At relatively high attack angle this result was quite important to confirm that the NACA air intake is still receiving a good amount of ram air to cool down the engine compartment.

A closer look at the flow pattern incoming the NACA air inlet is provided in Fig. 10 (a) and (b). By analyzing the flow's path lines, it is possible to see how the airflow behaves when captured by the NACA and the "amount" of spilled flow left behind it.

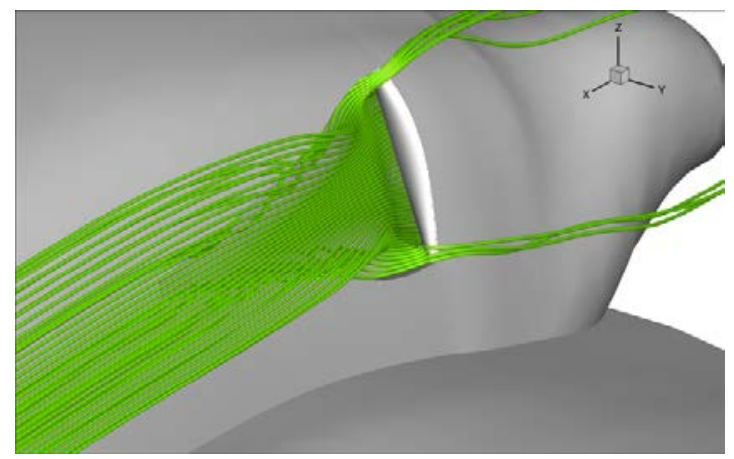

(a) $\alpha=2^{\circ}$

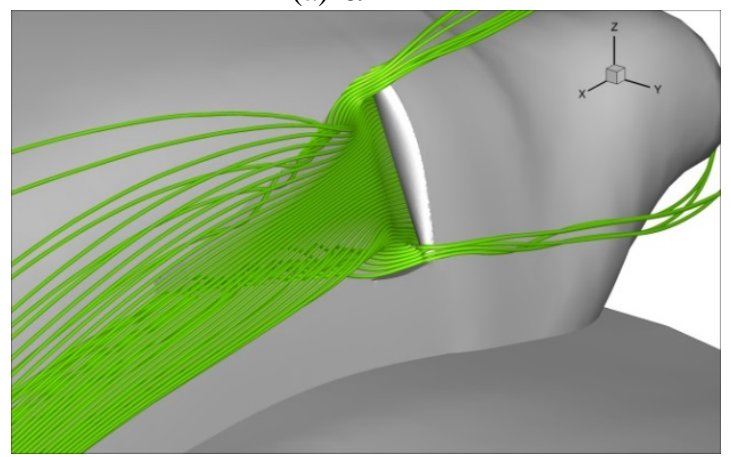

(b) $\alpha=15^{\circ}$

Figure 10. Spillage effect for the two test-cases.

The path lines in Fig. 10 indicate that the air is being spilled and therefore not all of the NACA area is useful causing a drop in efficiency and also an increase in drag, more specifically in the spillage drag component.

The NACA efficiency is given by the relationship between the dynamic pressure at the throat and the dynamic pressure at infinity, according to:

$$
\eta_{t h}=\frac{P t_{t h}-P S_{\text {inf }}}{P t_{\text {inf }}-P S_{\text {inf }}}
$$

The contours of dynamic pressure in the NACA's throat region are illustrated in Fig. 11. The global efficiency at the throat was numerically calculated by summing the local $\left(\eta_{\text {th }}\right)$, according to Eq. (8) in each node at that location. These results are summarized in Table 3.

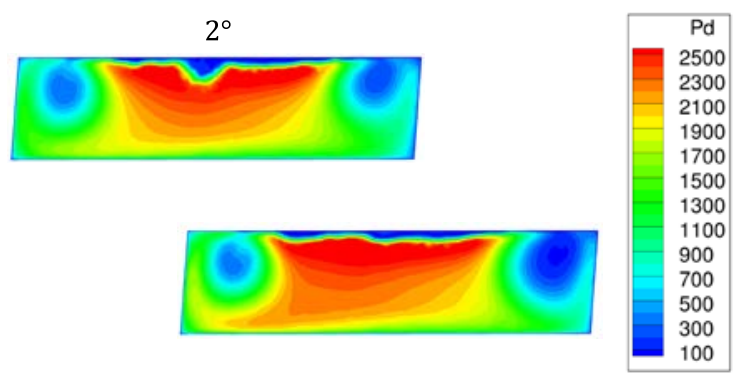

Figure 11. Dynamic pressure contour in the throat of the NACA air intake.

At cruise $\left(\alpha=2^{\circ}\right)$, there is almost a symmetric flow at the throat with the presence of a pair of vortices generated at the entry plane of the NACA. These vortices are identified by the low values in the dynamic pressure plots. With this flow pattern it is possible to affirm that there is little loss, the air inlet works very well in the recovery of pressure to the duct inside, due to the geometry of the aircraft which helps in the flow stream to the air inlet. The result achieved in this work was similar to the data obtained by Silveira et al. (2017).

By using the mean values of dynamic pressure $\left(P_{D}\right)$ in the intake throat and its value far away from the aircraft (far field), it was possible to calculate the intake efficiency from Eq.(8). The results are shown in Fig. 12.

Table 3. Mean Dynamic Pressure $\left(\mathrm{P}_{\mathrm{d}}\right)$ in $[\mathrm{Pa}]$, measured on the throat.

\begin{tabular}{cc}
\hline AOA (Attack Angle) & Dynamic Pressure [Pa] \\
\hline $2^{\circ}$ & 1472.388 \\
$15^{\circ}$ & 1537.987 \\
\hline
\end{tabular}

The uniformity of results over the flight conditions is desirable for this problem. Great changes in efficiency could mean that the intake is wrongly placed in the fuselage. In fact, as it can be confirmed by results in Table 3, the dynamic pressure kept almost uniform in both conditions investigated leading to inlet efficiency around $70 \%$ for the two cases investigated.

It is important to analyze this quantitative result for efficiency looking to the flow pattern in the throat region for these two conditions. As seen in Fig. 11, in cruise condition there is the appearance of a pair of counter-rotating vortices with the flow pattern almost symmetrical in the throat plane. The higher the strength of these vortices the lower the efficiency is, since less dynamic pressure is recovered. At the 
critical AOA condition $\left(\alpha=15^{\circ}\right)$, it is possible to see the asymmetry in the incoming flow at the inlet entry plane.

\section{Naca efficiency $(\eta)$}

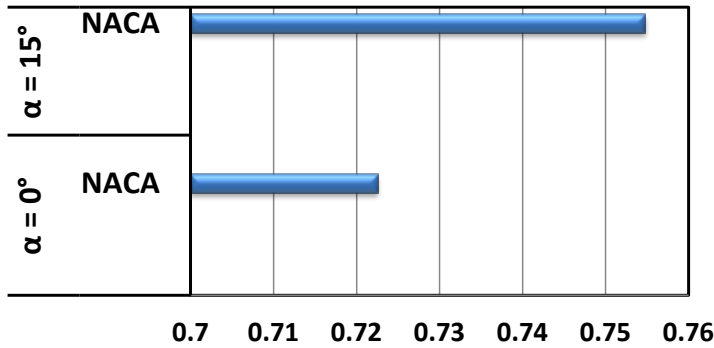

Figure 12. NACA air intake efficiency for $\alpha=2^{\circ}$ and $\alpha=15^{\circ}$.

The results generated in this analysis is different from those of Silveira et al.(2017) in the way that they did not take into consideration the canard in the fuselage. Without the canard, the streamlines were following completely the fuselage, the flow was seen with a little disturbance and interference all the way to the NACA entry. This led to a higher efficiency for the NACA air intake around 83\%. It is also important to notice that in the work of Silveira et al. (2017) the NACA air intake was designed to achieve its maximum efficiency.

Nevertheless, at the critical AOA condition, it was possible to see the asymmetry in the incoming flow at the inlet entry plane in both cases. However, in the work of Silveira et al. (2017) it was possible to see only one vortex being formed and passing by the throat, although with higher strength. In that case, the efficiency decreased to $63 \%$. Surprisingly, the presence of the canard in the fuselage helped to improve the flow at the rear part of the airplane at high attack angles. As seen in Fig.9 and Fig.10, the flow was almost similar to the cruise condition with asymmetry only in the vortex strength which led to a better pressure recovery at the throat.

By analyzing all the data presented in this investigation it is possible to affirm that the new NACA air-intake provided a reasonable efficiency in different flight conditions. Despite the increase in the drag estimate for the NACA air inlet, when compared to the work of Silveira et al. (2017) the flow pattern is well organized and the efficiency is acceptable for design.

The main concern in this design was to offer all mass flow to the engine compartment, in order to cool it down. Based on the engine data and manufacturer's specification, additional semiempirical and CFD simulations may be necessary to evaluate these quantities. The approach taken herein was quite acceptable in order to check new designs for the air-intake to be implemented in this aircraft. A further step will be the inclusion of different shapes of air inlets, such as scoops. In this case, a more refined analysis should take place in order to capture with more precision the drag force.

\section{CONCLUSIONS}

This paper has presented a numerical investigation of the flow inside a NACA air intake. This investigation was performed at Mach number 0.178 on a resized design based on previous works to incorporate the air inlet in the Bumerangue EX-27 canard-type aircraft - Silveira et al. (2017).

Due to the need of using a more powerful engine in this aircraft a new air inlet design was chosen according to the demanding mass flow in the engine compartment. A semi-empirical approach through the ESDU (Engineering Science Database Unit) coupled with CFD simulations were applied to re-design and select this NACA air inlet to operate at different flight conditions.

The numerical study was performed using CFD++ ${ }^{\circledR}$ commercial software through the k $\omega$-SST turbulence modeling with the discretization of the complete aircraft. What was different from this approach was that the front wing (canard) was taken into account. The results achieved in this work are closer to what is expected during the operation of the aircraft. As a conclusion, the air inlet efficiency is highly dependent on the incoming flow and the canard changed the flow pattern at the NACA air entry plane. The re-sizing of the NACA and the influence of the canard in the main flow led to an efficiency of $72 \%$ at cruise condition and around $75 \%$ in the critical condition at AOA 15 degrees. The presence of the front wing (canard) has helped to divert the flow into the air inlet at high angle of attack, thus not diminishing the NACA's efficiency. The uniformity of results over the flight conditions is desirable for this problem because allow the airplane to operate with safe margins of temperature in the engine compartment, assuming that it is completely refrigerated by the air stream.

All the data presented in this investigation is complementary to the work of Silveira et al. (2017) and helped the development of a Brazilian canardtype aircraft design. The selected NACA air-intake provided a satisfactory efficiency (nearly 74\%) in different flight conditions. Despite the increase in the drag estimate for the NACA air inlet, when compared to the work of Silveira et al. (2017) the flow pattern was well organized and the efficiency was acceptable for keeping the design.

This study also indicates that the procedure used in this work is acceptable as an engineering tool, with relatively low cost, for design selection and indicative of design trends. Further work may also apply to improve the aircraft's configuration.

\section{ACKNOWLEDGEMENTS}

The authors acknowledge with gratitude the 
support of CPAERO - Experimental Aerodynamics Research Center at Federal University of Uberlândia for carrying out this work. We also would like to thank the collaboration with the Brazilian Aircraft Factory (FABE).

\section{REFERENCES}

Silveira, B. H., Souza, P. R. C., and Almeida, O., 2017, Numerical Investigation of a NACA Air Intake for a Canard Type Aircraft, Int. Journal of Advanced Engineering Research and Science (IJAERS), Vol. 4, Issue-5.

Taskinoglu, E. S., and Knight, D., 2002, Numerical Analysis of Submerged Inlets, in: 20th AIAA Applied Aerodynamics Conference, St. Louis, Missouri.

Sun, G., and Guo, R., 2005, Numerical Analysis and Experimental Validation of a Submerged Inlet on the Plane Surface, Chinese Journal of Aeronautics, Vol. 18, No. 3.

Shams, T. A., and Masud, J., 2015, Steady Analysis of NACA Flush Inlet at High Subsonic and Supersonic Speeds, Proceedings of the World Congress on Engineering, Vol. II.

Nogueira, de F. W., and Oliveira, G. L., 2002, Analise de Entradas de Ar Tipo NACA com Gerador de Vórtices, in: 9th Brazilian Congress of Thermal Engineering and Science, ENCIT 2002, Caxambu, MG. (in Portuguese)

Pignier, N. J., O' Reilly, C. J., and Boij S., 2016, Aerodynamic and Aeroacoustic Analyses of a Submerged Air Inlet in a Low-Mach-number Flow, Computers and Fluids, Vol. 133, pp.15-31.

ESDU, 1986, Drag and Pressure Recovery Characteristics of Auxiliary Air Inlets at Subsonic Speeds, Item No. 86002 with Amendments A and B, July 1996, Engineering Sciences Data Unit, London.

Metacomp technologies inc., 2009, user's manual.

Menter, F. R., 1993, Zonal Two Equation k- $\omega$ Turbulence Models for Aerodynamic Flows, American Institute of Aeronautics and Astronautics Paper 93-2906.

Menter, F. R., 1994, Two-Equation EddyViscosity Turbulence Models for Engineering Applications, American Institute of Aeronautics and Astronautics, Vol. 32, No 8. pp. 1598-1605. 